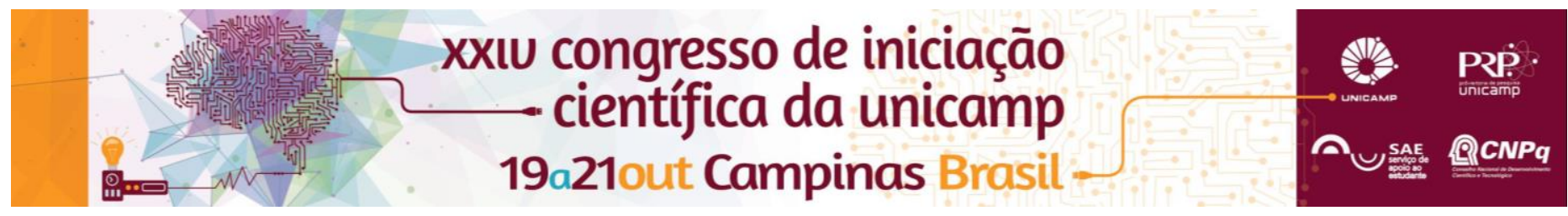

\title{
Variáveis sócio-demográficas e clínicas relacionadas ao Diabetes-related distress em pacientes atendidos na atenção terciária
}

\author{
Flávia C. Zanchetta*, Maria Helena de Melo Lima, Danilo D. Trevisan, Priscila P. Apolinario, Juliana B. da Silva
}

\begin{abstract}
Resumo
O objetivo deste estudo é avaliar a relação entre o diabetes-related distress com as características sócio-demográficas e clínicas em pacientes com diabetes mellitus tipo 2 (DM2). Trata-se de um estudo transversal que utilizou um banco de dados secundários de um estudo prévio realizado em hospital terciário. Os pacientes selecionados responderam a um questionário relativo às características sócio-demográfico-clínicas e, em seguida, aplicou-se o instrumento Diabetes Distress Scale em sua versão brasileira (B-DDS). Os resultados sugerem que as variáveis sócio-demográficas e clínicas atuaram como preditores relativamente fracos para o estresse relacionado ao diabetes. Os profissionais de saúde devem estar atentos para identificar os pacientes os quais o DM2 constitui um impacto psicológico negativo auxiliando-Ihes no controle de sua doença por meio de programas e intervenções que ofereçam o suporte necessário.
\end{abstract}

Palavras-chave:

Diabetes Mellitus, Estresse, Enfermagem.

\section{Introdução}

O Diabetes Mellitus Tipo 2 (DM2) representa um relevante problema de saúde pública no mundo. O principal objetivo do tratamento da doença é manter o controle glicêmico para a prevenção de suas complicações. Para isso, o indivíduo diabético necessita gerenciar e acompanhar sua doença. $O$ desafio para o monitoramento do DM2 e a possibilidade de complicações à medida que o DM2 progride podem acarretar em uma condição denominada diabetes-related distress caracterizada como uma resposta emocional para as diferentes situações com que o sujeito com DM2 lida em seu cotidiano que resultam em sentimentos negativos os quais interferem no controle da doença. $O$ objetivo deste estudo é avaliar a relação entre o diabetes-related distress com as características sóciodemográficas e clínicas em pacientes com DM2.

\section{Resultados e Discussão}

Estudo transversal que utilizou banco de dados provenientes de uma pesquisa conduzida no Hospital de Clínicas da Unicamp. Cento e trinta pacientes responderam a um questionário relativo às características sócio-demográficas e clínicas e ao instrumento Diabetes Distress Scale em sua versão brasileira (B-DDS). O B-DDS possui 17 itens subdivididos em quatro escalas: carga emocional, insegurança relacionada ao médico, estresse relacionado ao regime terapêutico e estresse nas relações interpessoais. As variáveis qualitativas foram analisadas segundo estatística descritiva e para as variáveis quantitativas calculou-se medidas de média e desvio padrão. Também foram aplicados cinco modelos de regressão linear múltipla considerando os escores dos domínios com as variáveis dependentes e independentes do modelo.

Tabela 1. Características sócio-demográficas e clínicas associadas com os domínios do B-DDS.

\begin{tabular}{|c|c|c|c|c|}
\hline $\begin{array}{c}\text { Variável } \\
\text { dependente }\end{array}$ & $\begin{array}{c}\text { Variáveis } \\
\text { independentes }\end{array}$ & Coef. & $p$-valor & $\mathrm{R}^{2}$ \\
\hline $\begin{array}{c}\text { Carga } \\
\text { emocional }\end{array}$ & $\begin{array}{l}\text { Trat. INS (ref.: } \\
\text { Sim) }\end{array}$ & $-0,55$ & 0,0010 & 0,13 \\
\hline $\begin{array}{c}\text { Estresse } \\
\text { relacionado } \\
\text { ao regime } \\
\text { terapêutico }\end{array}$ & $\begin{array}{l}\text { Estado Civil } \\
\text { (ref.: com } \\
\text { companheiro) }\end{array}$ & -025 & 0,0110 & 0,05 \\
\hline $\begin{array}{l}\text { Estresse nas } \\
\text { relações } \\
\text { interpessoais }\end{array}$ & $\begin{array}{l}\text { Comorbidades } \\
\quad(\text { ref.: } \geq 3)\end{array}$ & $-0,13$ & 0,0175 & 0,04 \\
\hline \multirow{3}{*}{$\begin{array}{c}\text { Escore total } \\
\text { B-DDS }\end{array}$} & $\begin{array}{l}\text { Estado Civil } \\
\text { (ref.: com } \\
\text { companheiro) }\end{array}$ & $-0,16$ & 0,0230 & 0,13 \\
\hline & $\begin{array}{l}\text { Trat. DIE EX } \\
\text { (ref.: Sim) }\end{array}$ & 0,18 & 0,0180 & - \\
\hline & $\begin{array}{l}\text { Trat. INS } \\
\text { (ref.: Sim) }\end{array}$ & $-0,20$ & 0,0030 & - \\
\hline
\end{tabular}

\section{Conclusões}

As variáveis sócio-demográficas e clínicas são preditores relativamente fracos para 0 estresse relacionado ao diabetes mellitus. O significado do escore total do B-DDS representa estresse moderado na amostra deste estudo. O domínio carga emocional apresenta os maiores escores indicando, desta forma, maior estresse neste quesito. Os profissionais de saúde devem esforçar-se para identificar pacientes os quais 0 DM2 constitui um impacto psicológico negativo e, além disso, devem ajudá-los com o controle de sua doença e referenciá-los para programas que podem oferecer suporte necessários.

\section{Agradecimentos}

Serviço de Apoio ao Estudante (SAE - UNICAMP).

Polonsky, W.H.; Fisher, L.; Earles, J.; Dudl, R.J.; Lees, J.; Mullan, J.; Jackson, R.A. Assessing psychosocial distress in diabetes: development of the diabetes distress scale. Diabetes Care. 2005;28(3):626-31.

Apolinario, P.P.; Trevisan, D.D.; Rodrigues, R.C.M.; Jannuzzi, F.F.; Ferreira, J.F.; Oliveira, H.C.; et al. Psychometric Performance of the Brazilian Version of the Diabetes Distress Scale (B-DDS) in Patients with Diabetes Mellitus type 2. Journal of Nursing Measurement.2016; in press. 